\title{
Editorial Note: Binary Representation Learning for Large-scale Multimedia Applications
}

Published online: 22 March 2019

C Springer Science+Business Media, LLC, part of Springer Nature 2019

Multimedia Tools and Applications gratefully acknowledges the editorial work of the scholars listed below on the special issue entitled, "Binary Representation Learning for Large-scale Multimedia Applications."

Of 47 papers submitted to this issue, 21 were eventually accepted after a stringent peer-review process.

\section{Dr. Lei Zhu (Managing Guest Editor)}

School of Information Science and Engineering

Shandong Normal University, China

leizhu0608@gmail.com

\section{Dr. Xiaojun Chang}

Language Technologies Institute

Carnegie Mellon University, USA

cxj273@gmail.com

\section{Dr. Fumin Shen}

School of Computer Science and Engineering University of Electronic Science and Technology of China, China fumin.shen@gmail.com

\section{Dr. Zhiyong Cheng}

School of Computing

National University of Singapore, Singapore

jason.zy.cheng@gmail.com

Publisher's note Springer Nature remains neutral with regard to jurisdictional claims in published maps and institutional affiliations. 